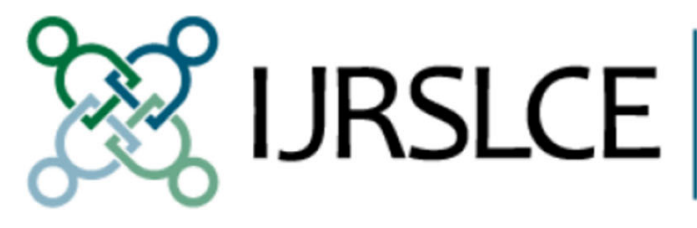

\author{
International Journal \\ for Research on \\ Service-Learning \& \\ Community Engagement
}

\title{
Value Added: Service-Learning Outcomes for Physical Therapy Students and Community Partners in Belize
}

\section{Candace Beitman \\ Julie Gahimer \\ William Staples}

This article was originally published at:

https://journals.sfu.ca/iarslce/index.php/journal/article/view/120/75

Recommended Citation

Beitman, C., Gahimer, J., \& Staples, W. (2015). Value added: Service-learning outcomes for physical therapy students and community partners in Belize. International Journal of Research on Service-Learning and Community Engagement, 3(1), Article 14. 


\title{
Value Added: Service-Learning Outcomes for Physical Therapy Students and Community Partners in Belize
}

\author{
Candace Beitman \\ Julie Gahimer \\ William Staples \\ University of Indianapolis
}

\begin{abstract}
This study comprised a follow up to a two-week interdisciplinary service-learning (SL) trip to Belize for graduate students from a private Midwestern university. Trip participants engaged in SL activities with multiple partnering agencies in various locations. The purpose of the study, which employed a qualitative, constructivist, focus-group design, was to explore the perceptions of students and community partners about the services provided. Data were analyzed for common themes using line-by-line and constant comparative methods. Six themes emerged from the data. Community partners complimented the education and training provided, and requested additional time and programming for future visits. Some identified the need for increased collaboration and additional preparation of students prior to the visit. Students demonstrated increased appreciation for interdisciplinary practice, enhanced professionalism, and greater sensitivity to cultural differences, and expressed their desire to participate in future international service trips. These findings supported the conclusion that interdisciplinary international SL activities are mutually beneficial to students and community partners.
\end{abstract}

Keywords: service-learning, community engagement, international, interdisciplinary

The developing country of Belize, formerly British Honduras, rests just south of the easternmost reaches of Mexico on the Caribbean Sea in Central America. Belize, the only English-speaking country in Latin America, acquired its independence from Great Britain in 1981. Since that time, Belizeans have struggled to rebuild and modernize the country's sociopolitical and medical infrastructures.

Belizean health care can be divided into two types of services: governmental and private. The Ministry of Health oversees all government-provided health care, on which the majority of Belizeans depend because the access to services is virtually free, unlike private health care services. Five out of the six districts in Belize have government-run regional hospitals with outpatient clinics and inpatient services. Some private hospitals exist for people who have private insurance or are able to afford independently the cost of medical care. Smaller villages may have a health care center or health post staffed by a nurse (R. Petrof, personal communication, December 9, 2010).

The government, through the Ministry of Health, allocates an annual budget to cover the cost of physicians, nurses, medical equipment, medications, and any 9other services provided through these hospitals and clinics. People can access out-patient clinics on weekdays to see a physician at no charge. Common medications are also given free of charge at the government pharmacy located at each hospital. Other free health care services include pre- and post-natal care for mothers, along with vaccinations for children from birth to five years old. Very few employers offer health insurance to their workers; 
however, the government (the country's single largest employer) and a few larger organizations include health insurance as a benefit to their employees. If medical care were not in large part free, many people would not have access to even basic health care.

Access to rehabilitation services in Belize is bleaker. People with acute or chronic conditions in need of rehabilitation services must generally travel elsewhere (e.g., the

U.S. or Guatemala) for such care, primarily because there are few practicing physical therapists who live and work in the country on a full-time basis (R. Petrof, personal communication, December, 2010). Moreover, there are no academic programs to train physical or occupational therapists. Typically, primary care providers are regional rehabilitation field officers (i.e., home care providers employed by Care Belize) or itinerant resource officers (i.e., National Resource Center for Inclusive Education, or NaRCIE, staff) who oftentimes have high caseloads of children and little more than a high school education. Thus, most health care agencies in Belize must rely on missionary organizations and other humanitarian groups, or not-for-profit or university-guided programs to enhance their programming and to provide skilled therapy services to their clients.

\section{International Service-Learning}

The mission of the World Confederation of Physical Therapy (WCPT) is to support physical therapists in expanding their practice borders in order to provide professional services to persons in underserved national and international settings. Today's occupational therapy (OT) and physical therapy (PT) students are preparing to enter a complex health care system; thus, they must understand the intricacies of international health care and become global citizens. The use of service-learning (SL) as a pedagogy in the education of occupational therapists and physical therapists to achieve this end has increased exponentially in the last decade, and outcomes of international cultural immersion experiences clearly reflect the power of SL in the development of core professional competencies. For example, Barker et al. (2010) and Pechak and Thompson (2009) noted many benefits of a structured international servicelearning (ISL) approach for OT and PT students, respectively, including the enhancement of transformative thinking or thinking "outside the box," altruism, confidence, and the interconnection between personal and professional development. Other researchers have observed that ISL experiences are linked to advanced critical thinking, professional behavior, and client advocacy skills among students in health profession programs (Harris, Sheehan, Dillbeck, Keane, \& Goodwin, 2011; Mu, Coppard, Bracciano, Doll, \& Matthews, 2010;; Pechak \& Thompson, 2009, 2010). Although it is clear that PT students benefit markedly from service-learning in national and international community-based settings, practitioners who are "pioneers" in developing international settings where limited to no routine habilitation and rehabilitation programs exist are still discovering best models for interdisciplinary OT and PT service provision. In order to address this gap, researchers in this study were interested in better understanding the experiences of both PT students and agency representatives participating in a novel interdisciplinary service-learning trip.

Students in the Doctor of Physical Therapy (DPT) program at the University of Indianapolis had the opportunity to enroll in a post-professional course entitled "Seminar in International Practice" taught by the first author during the summer of 2012 and to complete service-learning and/or professional development curriculum requirements in Belize as part of subsequent courses taught by the second and third authors. The SL opportunity is included as an elective for entry-level and post-professional OT and PT students; thus, students can earn one credit hour for service-learning and three credit hours for professional development by participating in the International Practice seminar and trip. The university has a well-organized International Division-which assists with the coordination and financing of international service-learning trips - and a long-standing relationship with the executive director of an educational travel program, a Belize resident who maintains contact with our partners and manages incountry accommodations, travel, cultural education, and travel experiences, and ensures travelers' safety and access to emergency health facilities throughout the trip. 
In July of 2012, an interdisciplinary group representing the College of Health Sciences (CHS) traveled to Belize for a two-week service-learning and service-provision experience. Trip participants consisted of three OT and two PT Doctor of Health Science (DHS) students, five entry-level DPT students, one practicing PT guest, and one entry-level OT student guest from another university. The trip was led by one OT and one PT faculty member from the University of Indianapolis. Partnering agency participants included two to six staff members from each of three primary national organizations: Care Belize, HelpAge Belize, and NaRCIE in San Ignacio, Belmopan, and Belize City, Belize. Care Belize provides services to children with disabilities aged birth to school-age. HelpAge Belize (http://www.helpage.org/helpageusa/where-we-work/caribbean/belize), a non-governmental umbrella organization, provides adult day care, home care, and residential services for persons aged 55 and older. Staff at NaRCIE work "to provide educational services including screening, diagnostic assessments, teacher training, parent and school support and specific therapies for students with special needs" (Ministry of Education, 2013). Agency participants represented a variety of educational levels and held various roles within their organizations (e.g., director, rehabilitation field officer, itinerant resource officer, teacher, etc.).

Faculty, entry-level students, and practicing therapists/post-professional students provided a combination of direct intervention, caregiver education and training, and resource provision using a combination of Western practice, community-based rehabilitation, and health education approaches. Occupational therapy and physical therapy services were provided in homes, adult day care centers, and extended care facilities in multiple communities across Belize. Faculty members, the PT guest, and the post-professional students acted as supervisors for the entry-level students and led the four- to sixmember interdisciplinary work teams assigned to each agency. The number of home health and residential sessions varied according to location. Each team typically conducted four to six home health visits and 10 to 12 therapy sessions with nursing-home residents per day. These differences were due to the increased travel times required for home visits in more remote areas. Other than at one residential facility, where residents with disabling conditions were each seen for therapy on four consecutive days, teams were able to provide intervention and training sessions on a one-time-only basis.

\section{Purpose}

The purpose of this qualitative focus-group study was to explore the thoughts and feelings of entry-level PT students and Belizean agency partners regarding a two-week interdisciplinary service-learning and service-provision pilot experience in a country where few rehabilitation therapy services are available. The researchers aimed to gain insights about the benefits and challenges of this type of program, and to gather recommendations for enhancing future interdisciplinary international programs. Thus, the research questions included:

(1) How do entry-level DPT students describe their interdisciplinary international experience? What do they identify as benefits, challenges, and recommendations for improvement?

(2) How do community partners describe the experience? What do they identify as benefits, challenges, and recommendations for improvement?

\section{Methods}

\section{Study Design}

The researchers employed a qualitative multiple focus-group design to gather data from the PT students and the agency partners in separate cohort groups. Consistent with our study design, focus groups were used to gather data from small groups of personnel in each individual agency and from entry-level PT student participants. Focus groups are recommended for exploratory studies in order to gain more depth into topics about which little is known. According to Gill, Stewart, Treasure, and Chadwick (2008), responses in a focus group tend to be open-ended, broad, and qualitative, and to build upon one another, encouraging quieter participants to involve themselves in the discussion as well. 


\section{Participants.}

Study participants were selected from a sample of convenience. Selection criteria included being a participant (either a student or agency staff member) in the 2012 OT/PT service-learning and serviceprovision trip to Belize, and the ability to understand and speak English. All five entry-level DPT students who were trip participants volunteered to take part in the study. Two males and three females in their mid-20s - all Caucasian-comprised this group. Final course assignments and grades were fully completed prior to the interview process to minimize coercion effects on the part of the first author. Seven trip participants (i.e., the DHS students, the OT student, and the PT guest) were excluded from the study due to the geographical distances that would have been required for them to travel to the campus for focus-group sessions and IRB concerns regarding lack of compensatory funds for travel expenses.

The community agency sample consisted of two to five directors and/or staff members from each of five separate agencies in three locations, including NaRCIE and CARE-Belize (Belize City), HelpAge Belize (Belize City and Belmopan), and a retirement center/nursing home (San Ignacio).

\section{Procedures.}

The researchers conducted a total of 10 focus-group sessions, including five face-to-face sessions conducted by the first and second authors with five partnering Belizean agencies two months post-trip at each agency site. Follow-up face-to-face sessions were conducted with three of those agencies by the first author and the Belizean trip liaison five months post-trip at their respective sites for the purposes of member-checking regarding data accuracy and expansion of information in preliminarily identified theme areas.

One initial and one follow-up focus-group session were conducted with students on the university campus at six and nine months post-trip, respectively. The interviews were staggered to accommodate students' academic and clinical schedules and availability, and to give them time to integrate their thoughts and gain additional clinical experiences for comparison to those encountered in Belize; focusgroup timing differences were also due in part to researchers' availability to participate in travel meetings. Data saturation was reached during the final student focus-group meeting. Researchers used this final focus group for member-checking purposes to review and revise preliminary themes isolated during researchers' data analyses.

All focus-group interviews were conducted face to face in English, utilizing a semi-structured interview guide with descriptive and structural questions developed by the researchers to encourage personal insight and garner recommendations for improvement from the participants (see Appendix). An example of a question asked during a student focus group was, "What are your perceptions or thoughts regarding the information or services you or your co-students or professional colleagues/supervisors provided to care recipients or caregiver staff of our partnering agencies in Belize?" An example of a question asked of the agency participant groups was, "What are your perceptions or thoughts regarding the information or services provided to you or your care recipients by the students and faculty from the university?"

Preliminary results were analyzed and themes generated within two weeks following each focusgroup session, and they were reviewed and revised on an ongoing basis throughout the study. Follow-up questions were developed as a result of repeated analyses for use in subsequent focus-group interviews.

The researchers took notes during the interviews, which were audiotaped and then transcribed verbatim by graduate students not involved in the study. Dependability was enhanced through use of an audit trail. The three researchers independently read and coded transcripts from each interview using open line-by-line coding with margin notations and constant comparative methods to capture key words and phrases. Researchers met several times subsequently to discuss these key words and phrases, to recode themes, and to reach consensus around emerging themes generated from the data. Additionally, researchers revisited the literature following the identification of themes in order to confirm study results, and an external audit was conducted with 41 students in two of the first author's graduate research courses 
to further enhance trustworthiness of study results. This audit consisted of individual critical analyses using a form for qualitative research appraisal adapted from Letts et al. (2007).

\section{Results}

Five common themes were identified by both groups. These themes included: lack of resources (including time, equipment, materials, access to health care, and transportation), education/training needs, cultural sensitivity and communication, pre-planning, and sustainability. An additional theme of professional development was identified by the student group.

\section{Lack of Resources}

Issues of health promotion, wellness, and disease and disability prevention are slowly gaining attention on a national level in Belize. However, not all Belizeans are privy to health-related information, and many lack understanding of basic health promotion and chronic illness management techniques. Information about preventative measures and/or financial resources to access such information is also limited. Thus, students made such recommendations for future trips as, "We need to not forget the idea of [basic] health and wellness ... [including] water consumption." They also mentioned that there was a "time crunch [because it was] hard to find a balance with treatment and wellness initiatives."

Because the majority of the partners were new to the service-learning program at that time, students had minimal initial understanding of the level of health literacy of program participants and only a vague idea of what agency personnel wanted in terms of education of their staff. Agency personnel, likewise, had minimal to no understanding of what the disciplines of occupational and physical therapy were about, and what the therapists and students could offer.

Similarly, students and faculty had minimal pre-trip knowledge of the equipment we would need for our interventions in Belize. Although trip participants were able to bring some additional donated items, such as Theraband ${ }^{\circledR}$ and splinting materials, as well as a few items requested in advance (e.g., audiotapes, craft supplies, etc.), we were largely unaware of other needs that became quickly apparent once we were in-country. As a result, therapists and students needed to work together creatively to resolve issues related to mobility and functional activities of daily living. Some of the adaptations made to and with average household items (e.g., spoons and bottles) transformed those objects into therapeutic tools. For example, the co-leader modified a spoon by melting it over an open flame and using a drawer handle to bend it at a 90- degree angle, thereby allowing a nursing home resident to independently feed himself. A pediatric team molded hardening materials around the necks of locally made beer bottles, then used the molds to maintain open palms in smaller patients' hands. Scrap splinting materials were also used to fabricate an ankle-foot orthosis using a large pot and boiling water.

Students reflected on the lack of materials for therapeutic intervention and on the resourcefulness necessary for this type of international practice: "It's hard to know the resources that you need prior to going." One student commented:

Just being more resourceful because they do not have a lot, just being able to meet people where they are ... not just saying what we think is important, but what somebody is actually going to be able to take away from our help and ... being more resourceful with our interventions ... being able to tailor them to that specific population or person for their benefit.

Lack of time (for therapy and caregiver training) was also noted as a concern among students and agency staff. Therapists and students were challenged to address the needs of each child adequately within the 45- to 60-minute treatment time, especially given the resource insufficiency described earlier and the acuity level of several of the children: "With some kids, longer time is needed."

A typical education/training session with agency partners lasted two to three hours. Because faculty and students were largely unaware of the depth of knowledge of the agency's staff prior to the trip, they provided basic information first; the time allotted for in-services was not sufficient to address more 
complex information or to deal with specific caregiver concerns. Not surprisingly, agency partners noted the brevity of the training: "They just gave us a basic overview. Time was not in our hands, so ... they just had to rush."

\section{Education and Training}

The theme of education and training arose in both the students' and the partners' comments in terms of the benefits and challenges of the educational interventions and workshops provided. Students felt that the "educational interventions were helpful, giving [caregivers] educational information, handouts, etc.," and that "the panel discussion was excellent: diet, nutrition, stroke, Alzheimer's."

Entry-level students were used to the professional terminology they had been using in their academic work. They were challenged, therefore, to explain disease and disability processes and interventions to those with limited health literacy-and celebrated the development of their budding cross-cultural communication abilities. For example, one student expressed pride in "being able to explain what is going on." Students also commented on the overwhelming need for occupational and physical therapy and therapists in Belize, and the potential for future rehabilitation practitioners to achieve stellar therapeutic outcomes with underserved populations in the country: "A big part of the education [was] getting PT and OT into their minds" (since habilitative and rehabilitative therapy is relatively unknown in Belize). "Anyone in the rehab field can have a huge impact down there."

Agency directors also remarked on the value of the educational interventions offered by faculty and students. For instance, informal volunteer and familial Belizean caregivers were unaware of body mechanic techniques and proper footwear for preventing injury to themselves in transferring persons from bed to wheelchair to toilet, etc. The director of one HelpAge facility reported that volunteer agency caregivers "were not lifting properly, not twisting properly and wearing the wrong shoes" prior to the education and practice session provided by therapists and students: "[The students and faculty] taught them how to tweak [modify] a movement and I [the director] was 'blown away' by ... what a difference it made." Another agency director complimented the educational session provided at her facility during the second focus-group meeting and voiced her certainly that her staff and parents of children with disabilities had gained valuable skills they would use in the future: "I am convinced that some of the skills you were able to show were retained by the rehab field officers as well as the parents."

Personnel from one agency commented that they would like additional training from future groups on wound care and wound prevention. CARE-Belize staff also expressed a desire to understand the reasoning behind the interventions that the students were teaching them: "Many times as an RFO [rehabilitation field officer] you know the activity(ies), but you cannot build upon them because you do not know the rationale behind them." Agency personnel also voiced a need for counseling for their care recipients and for the development of a caregiver support group for parents of children with disabilities because of the stigma and shame often experienced by families with children with disabilities in Belize.

\section{Cultural Sensitivity and Communication}

Understanding cultural differences and ways to effectively communicate with others was another recurring theme. As one student noted:

I personally developed a bit more selflessness, meeting [the clients] where they are...I think just people [being] flexible and being open to new cultures and new things and being able to take in as much as you can from the experience [was important]. You are learning from other PTs and OTs and then you get to learn from this different culture that you normally wouldn't get to experience andjust being open for that, and willing to take it all in.

These statements reflect cultural competence acquisition consistent with the American Physical Therapy Association's (2009) core values of altruism, inter-professionalism, and client-centered care.

Students' comments also illustrated Schön's (1983) concept of reflection in action, a skill that is 
typically not acquired until after the first year of professional practice. Students had to adapt to different situations on the spot versus waiting until they could problem solve solutions at a later time, which boosted their confidence and enhanced their communication and teamwork skills. For example, one student commented that "[we] had to adapt communication, [to be able to] identify what was going well and what was not." Other students reported that "communication was enhanced explaining to patients what [we] were seeing" and that they enjoyed "communicating with caregivers and with other health care members" (i.e., RFOs) because they realized that "communication was a huge aspect of what we want to accomplish down there" due to low health literacy in the general population. Several of the agency partners also commented on the degree to which the experience challenged students' cultural comfort and sensitivity: "[The students] were adjusting [to differences in living situations] ... maybe they didn't come knowing much about the culture, but they were respectful."

One issue stemming from cultural differences between our teams and Belizean caregivers concerned divergent approaches to working with clients. Using their Western lenses, our professionals were used to focusing more on individual therapy with children during treatment sessions and less on working with caregivers and families using a community-based rehabilitation approach, as is commonly practiced in a collectivist, familial society like Belize. Agency partners commented on this gap and the need to address the concerns of the parents within the treatment session. One partner commented: "In that hour it is not just about dealing with the child, but ... giving the parents their time as well." A second agency staff member stated, "Even in the first visit, you must build that rapport with the family instantly," and she observed that at times the parents "maybe did not know what to ask.... I felt like they held back a little.... In one visit the parents [didn't] open up."

\section{Pre-Planning}

Both students and partners discussed the need for additional information and educational materials prior to the service-learning experience. This is consistent with the findings of Reisch (2011) and Pechak and Black (2014). Specifically, students talked about the need to "learn about the country prior to going" and "see what they already know" because the "needs must match up"; "[service providers can do] more damage than good if those needs are not identified." One student reflected: "I guess once we got down there, we had to learn that on the fly, but if we had known ahead of time ... how to organize something like that - that would have helped out."

Partners likewise recommended that information be presented to staff based on current needs and knowledge, and they identified the need for pre-and post-intervention meetings to review information about each client and to discuss strategies and outcomes of interventions provided. Since this was our "maiden voyage" with an interdisciplinary team consisting of both students and post-professional practitioners, and because the majority of our partners were new to us in 2012, the authors and their Belizean liaison were unsure of the partners' needs going into this experience or of specific exercise and information handouts and home programs we should bring with us. This was partly due to our inability to communicate to our partners ahead of time what we could "deliver" based on our professional expertise and experience, but also to the partners' limited understanding of how OT and PT could work within their populations, and to the minimal information received from the partners (primarily diagnoses and ages of clients) prior to departure, despite numerous requests by our in-country educational travel liaison. Time constraints limited pre- and post-intervention meetings with agency caregivers; however, such meetings and documentation of services were clearly identified as essential components of international programs.

\section{Sustainability}

According to one student, "continued contact [with the partnering agencies] is very important, [in order to] create resources to give them and materials to use." Another student commented on the importance of providing additional materials to local caregivers and suggested that a rehabilitation certificate program "would be an excellent program to get running, not only for the awareness aspect, but for actually training these people and getting them out there so that they can do the rehabilitation when groups like us are not 
there."

All agency partners responded favorably to a question regarding whether they would be interested in some sort of continuing education offered more regularly than once per year; however, some voiced doubt about the feasibility of such a program given logistics related to time off from work and transportation for their staff and families if training sessions were provided at other times of the year besides summer (when $\mathrm{NaRCIE}$ teachers are required to attend approved training programs) or for longer periods of time.

\section{Professional Development}

The topic of professional development during the service-learning experience arose multiple times in the student focus groups, and included subthemes of comfort and confidence, skill development, and compassion and humility.

Regarding comfort and confidence, one student commented that this experience allowed him or her to put concepts and treatment principles learned in class together in order to view clients holistically within their cultural environments: "Going through the first year of PT school, you feel as if you are too busy to see the whole picture."

The more relaxed supervision style employed by the faculty also contributed to students' comfort and confidence levels. Although they were always on treatment teams with at least one practicing therapist, entry-level students were given freedom and sufficient opportunities to work with clients individually or in pairs at their level of expertise, which facilitated collaborative learning, self-confidence, and professional identity: "[You] didn't have a professor looking over your shoulder and grading you," and the experience "gave me more confidence [in] my judgment and clinical reasoning."

Several types of skill-based learning were reported in the focus groups. One student mentioned the writing skills required for documentation: "Writing the home exercise programs, coming up with ways to describe what we are doing" was difficult. A second student pointed out that "[my] educational abilities were enhanced describing musculoskeletal conditions." Students also discussed skill development in the areas interdisciplinary collaboration as a result of this experience. Finally, students reported gaining a sense of compassion and professional obligation to use their skills with persons in need in their own communities as well as with global citizens in need of habilitation and rehabilitation services: "Just ... realizing there is a need ... globally ... for rehabilitation and just stepping out of your comfort zone and your daily schedule [to] think about helping somebody in your community ... or abroad that could really use your skills to benefit them."

\section{Discussion}

Six primary themes evolved from the data, including lack of resources, education and training, cultural sensitivity and communication, pre-planning, sustainability, and student professional development. The findings indicate that the service-learning experience was a "win-win" since both students and community partners perceived it as beneficial.

Students reported enhanced professionalism, appreciation for interdisciplinary practice, and sensitivity to cultural differences. They felt challenged to "think outside the box" and be creative due to the scarcity of supplies and equipment, as demonstrated by their comments about adaptability, flexible attitudes, and the need to make decisions quickly on the spot. They commented on their desire to participate in future international service trips, indicating an increased awareness of global responsibility and level of comfort with international, interdisciplinary, and intercultural practice. Lastly, students identified skill development that is consistent with the core values of the PT profession, including confidence, humility and altruism, cultural sensitivity and intercultural communication, creativity, and resourcefulness.

Agency participants voiced positive impressions of the students and their skill sets, and provided advice to enhance students' cultural sensitivity prior to the trip. Findings indicated that there is a need for more information and planning before the trip. One of the primary challenges of developing and creating new therapy services in a developing country from afar, however, is the potential for unanticipated situations that 
may occur despite extensive planning procedures. To this end, trip leaders and their Belizean educational travel liaison are working to develop specific objectives and mechanisms for increased student understanding and knowledge about the myriad factors involved in cultural immersion in service-learning activities pre- and post-trip, as well as ways to facilitate increased between-trip collaboration with partnering agencies.

Community partners likewise perceived benefits for their staff and those whom they serve, and were desirous of future service-learning partnerships with our group. Partners clearly identified a need for habilitative and rehabilitative education and training of their itinerant and volunteer caregivers, teachers, and families. As a result, researchers and our educational travel liaison held meetings with the administration of a private university in Belize - which at that time was in partnership with our university - and developed an outline for a six-week rehabilitation aide course to be delivered on the Belizean university's campus. However, agency partners expressed concern about the feasibility of such a program, stating that their volunteers and other staff would be unable to afford the cost of such training, be hampered by transportation issues, be unable to take six weeks off from work at one time, and likely not receive additional compensation for this specialty certificate. Although it may seem logical to deliver at least some portion of such a course in an online format, the majority of persons (and one of our partnering agencies) in Belize do not have computers, and Internet service is unpredictable.

Potential alternative solutions discussed during subsequent service-learning trips have included the delivery of the six-week rehabilitative aide course by our university faculty in two-week increments and spread out over an entire year, and the formation of a consortia of OT and PT programs at other U.S. universities to provide education and training at various agencies and locations in Belize at different times of the year. However, funding and time off from work for professionals to provide such services, though not insurmountable, are primary barriers to implementation of such services. Nonetheless, researchers are committed to finding a workable solution to allow for more consistent, sustained OT and PT services with our agency partners in Belize.

Limitations of this study included the student participant sample of convenience and homogeneity. Neither entry-level OT students nor post-professional students (i.e., supervising therapists for the entry level students) were recruited to participate in the study in order to capture program impacts on a broad population or one with special characteristics. Thus, we cannot assume that the results are transferable either to these populations or to PT students or human service agencies in other international settings. Although the first author took steps to decrease her bias, the findings may reflect misperceptions about the meaning of focus-group results for both students and agency participants. There were no grades associated with this experience; nonetheless, students may have felt pressured to participate in the study due to their affiliation with the researchers, who were also their professors. Lastly, agency participants may have been hesitant to identify negatives associated with this trip for cultural reasons, not wanting to offend the researchers (a cultural faux pas for Belizeans) or jeopardizefuture service-provision trips.

\section{Conclusion}

Future research is needed to further investigate the impact of short-term international interdisciplinary service-learning and service-provision experiences for those who are receiving direct therapy services, and for entry-level OT students and practicing therapist supervisors. Additional studies should be conducted to further explore opportunities for sustainability of therapy services in developing countries where there are few practicing therapists and severely limited access to therapy services, and to further define best practices for interdisciplinary international work in these settings.

In today's complex society, it is increasingly evident that interdisciplinary OT and PT teamwork combined with an in-country liaison with multiple connections may provide an ideal mechanism to begin alleviating health concerns and disparities in international settings with limited health care services, and increase cultural competency and professional development of health professionals. Partnerships between universities and local health care agencies provide opportunities for OT and PT students to work on teams 
with practicing therapists to experience service-provision and service-learning activities with culturally diverse populations in international settings. Health care professionals are increasingly challenged to look beyond their geographic boundaries to provide therapy services to persons in need globally. Universities are uniquely situated to be able to provide service-learning experiences at home and abroad for students, faculty, and alumni in health care professions. Highly community-practice-oriented, university-based interdisciplinary international service-learning programs with strong in-country connections can be a conduit to achieving health care equity for populations in developing countries.

\section{Appendix}

\section{Semi-Structured Interview Questions}

For Students:

1. What are your perceptions, or thoughts regarding the information or services you or your co-students or professional colleagues/supervisors provided to care recipients, care givers, and/or club members of our partnering agencies and institutions in Belize last July?

2. How did this service-learning and service-provision experience impact your personal and/or professional development and (future) professional practice? (Do you think you will return to Belize or another developing country to provide professional service? Might you conduct research on topics related to collaborative international or interdisciplinary service-provision?)

3. What suggestions or recommendations do you have for us for future collaborative work or projects with our partners in Belize? (Would you recommend future such trips and continuation of the partnerships with the agencies, institutions, and/or clubs with whom we worked? What would you like to see changed, and how would you make that change happen?)

4. Is there anything we haven't asked you that you would like to add?

For Community Partners:

1. What are your perceptions, or thoughts regarding the information or services provided to you (or your care recipients, children, club members) by students and faculty from the University of Indianapolis last July?

2. What feedback have you gotten from the recipients of these services about the quality or helpfulness of the information or services provided? What aspects were good? What was missing, or not as good as you would have liked? (Was the time spent with your agency sufficient? Were students and faculty knowledgeable about topics presented, skilled in intervention and training techniques, respectful of any cultural differences?)

3. What suggestions or recommendations do you have for us for future collaborative work or projects with you? (Would you like us to come back/continue this partnership? What would you like to see changed?)

4. Is there anything we haven't asked you that you would like to add?

\section{Author Note}

Candace Beitman, School of Occupational Therapy, University of Indianapolis; Julie Gahimer, Krannert School of Physical Therapy, University of Indianapolis; William Staples, Krannert School of Physical Therapy, University of Indianapolis.

\section{Correspondence}

Correspondence regarding this article should be addressed to Candace Beitman, Associate Professor Emeritus, School of Occupational Therapy, College of Health Sciences, 1400 East Hanna Avenue, Indianapolis, IN 46227. Phone: (317) 946-6559. E-mail: cbeitman@uindy.edu 


\section{References}

American Physical Therapy Association. (2009). Professionalism in physical therapy: Core values. Retrieved from http://www.apta.org/uploadedFiles/APTAorg/About Us/ Policies/BOD/Judicial/ProfessionalisminPT.pdf

Barker, A., Kinsella, E. A., \& Bossers, A. (2010). Learning in international practice placement education: A grounded theory study. The British Journal of Occupational Therapy, 73(1), 29-37.

Bosworth, T. L., Haloburdo, E. P., Hetrick, C., Patchett, K., Thompson, M. A., \& Welch, M. (2006). International partnerships to promote quality care: Faculty ground work, student projects, and outcomes. Journal of Continuing Education Nursing, 37(1), 32-38.

Bourke-Taylor, H., \& Hudson, D. (2005). Cultural differences: The experience of establishing an occupational therapy service in a developing community. Australian Occupational Therapy Journal, 52, 188-198.

Curtin, A. J., Martins, D. C., \& Schwartz-Barcott, D. (2014). A mixed-methods evaluation of an international service learning program in the Dominican Republic. Public HealthNursing, 32(1), 58-67. doi: 10.1111/phn.12117

Gill, P., Stewart, K., Treasure, E., \& Chadwick, B. (2008). Methods of data collection in qualitative research: Interviews and focus groups. British Dental Journal, 204(6), 291-295.

Harris, S., Sheehan L., Dillbeck, A., Keane, P., \& Goodwin, S. (2011). Reaching out: Developing and implementing an international service learning program. OT Practice, 16(18), 19-22.

Hayward, L., \& Charrette, A. (2012). Integrating cultural competence and core values: An international service-learning model. Journal of Physical Therapy Education, 26(1),78- 89.

Humbert, T. K., Burket, A., Deveney, R., \& Kennedy, K. (2012). Occupational therapy students' perspectives regarding international cross-cultural experiences. Australian Occupational Therapy Journal, 59, 225-234.

Lattanzi, J. B. \& Pechak, C. M. (2012). Educating globally minded physical therapist students: Curriculum strategies to equip the next generation. Journal of Physical Therapy Education, 26, 55-60.

Lee, A. C. W., Litwin, B., Cheng, M., \& Harada, N. (2012). Social responsibility and cultural competence among physical therapists with international experience. Journal of Physical Therapy Education, 26(3), 66-73.

Letts, L., Wilkins, S., Law, M., Stewart, D., Bosch, J., \& Westmoreland, M. (2007). Guidelines for critical review form: Qualitative studies (version 2). Ontario, Canada: McMaster University.

Ministry of Education, Youth and Sports. (2013). National Resource Center for Inclusive Education. Retrieved from http://www.moe.gov.bz/index.php/education-services/education-support-servicesess/narcie

Mu, K., Coppard, B. M., Bracciano, A., Doll, A., \& Matthews, A. (2010). Fostering cultural competency, clinical reasoning, and leadership through internationaloutreach. Occupational Therapy in Health Care, 24, 74-85.

Nicholson, J. G. (2007). Hillside health care clinic: A rural Belize international preceptorship. The Journal of Physician Assistant Education, 18(2), 64-67.

Pechak, C., \& Thompson, M. (2009). International service- learning and other international volunteer service in physical therapist education programs in the United States and Canada: An exploratory study. Journal of Physical Therapy Education, 23(1), 71-79.

Pechak, C., \& Thompson, M. (2011). Going global in physical therapist education: International servicelearning in U.S.-based programmes. Physiotherapy Research International, 16(4), 225-236.

Pechak, C. M., \& Black, J. D. (2014). Proposed guidelines for international clinical education in U.S.based physical therapist education programs: Results of a focus group and Delphi study. Physical Therapy, 94(4), 523-533.

Reisch, A. R. (2011). International service-learning programs: ethical issues and recommendations. Developing World Bioethics, 11(2), 93-98.

Reynolds, P. J. (2005). How service-learning experiences benefit physical therapist students, professional development: A grounded theory study. Journal of Physical Therapy Education, 19(1), 41-54. 
Schön, D. (1983). The reflective practitioner: How professionals think in action. London: Temple Smith. Shalabi, N. (2013). Exploring community partners' perspectives of the nature of service-learning partnerships in Egypt. International Journal of Research on Service-Learning and Community Engagement, 1(1), 80-90.

Sloand, E., \& Groves, S. (2005). A community-oriented primary care nursing model in an international setting that emphasizes partnerships. Journal of the American Academy of Nurse Practitioners, $17(2), 47-50$. 